\title{
Risk Factors for Overweight and Obesity among Children and Adolescents in Bangladesh: A Hospital Based Study
}

\author{
MONIRA HOSSAIN ${ }^{1}$, ISMOT ARA ZANNAT ${ }^{2}$, SURAIYA BEGUM ${ }^{3}$, SHAHANA RAHMAN ${ }^{4}$
}

\begin{abstract}
Background: Childhood obesity is becoming an epidemic globally as well as in Bangladesh. Although several risk factors are identified for overweight or obesity, limited studies have been done in our country. The objective of this study was to identify the risk factors of overweight and obesity in children and adolescents in Bangladesh.

Methodology: It was a cross sectional study done in children, aged 5 to 16 years, attending the Paediatric Endocrine Clinic and Paediatric Outpatient Department, Bangabandhu Sheikh Mujib Medical University (BSMMU), Dhaka over a period of 18 months. Overweight and obese children as well as normal weight children were selected after considering inclusion and exclusion criteria. They were classified as case (overweight/obese) and control (normal weight) according to the Center's' for Disease Control and Prevention age and sex specific growth chart. Among a total of 150 children 100 were cases and 50 were controls.

Results: Majority of children in both the groups were male. Among cases $77 \%$ were obese and $23 \%$ were overweight. Analyzing the risk factors, it was found that first issue had 2.66 times, watching TV $>3 \mathrm{hr}$ had 4.47 times, breast feeding $<6$ month had 4.16 times, daily more caloric intake (approx.) had 17.36 times and maternal $B M I>24.9$ had 2.70 times increased risk to develop obesity.

Conclusion: The first issue, excess television watching, lack of exclusive breast feeding, excess calorie intake and having overweight/obese mother had higher risk to develop overweight or obesity in children and adolescents.
\end{abstract}

Keywords: Overweight, Obesity, Risk factors

\section{Introduction}

Childhood overweight and obesity is a rapidly increasing public health problem in both the developed and developing countries. ${ }^{1}$ It is now an emerging health problem in Bangladesh as well and increasing steadily, particularly in affluent society. ${ }^{2}$ The worldwide prevalence of childhood overweight and obesity is increased from $4.2 \%$ in 1990 to $6.7 \%$

1. Registrar, Department of Paediatrics, Shaheed Suhrawardy Medical College Hospital, Dhaka

2. Resident, Department of Paediatrics, Bangabandhu Sheikh Mujib Medical University, Dhaka

3. Associate Professor, Department of Paediatrics, Bangabandhu Sheikh Mujib Medical University, Dhaka

4. Professor, Department of Pediatrics, \& Pro Vice Chancellor (Academic), Bangabandhu Sheikh Mujib Medical University, Dhaka

Correspondence: Dr. Monira Hossain, Registrar, Department of Paediatrics, Shaheed Suhrawardy Medical College Hospital, Dhaka, Mobile: 88-01712084725, E-mail: moniradr@gmail.com Received: 24-06-2018 in 2010 and this tendency is anticipated to reach $9.1 \%$ by $2020 .{ }^{3}$ In developing countries the prevalence of obesity among children and adolescent was found to be as $22.1 \%$ in Brazil, $41.8 \%$ in Mexico, $19.3 \%$ in Argentina and $22 \%$ in India. ${ }^{4}$ In a countrywide epidemiological study showed that the prevalence of childhood overweight and obesity in Bangladesh was $9.5 \%$ and $3.5 \%$ respectively. ${ }^{5}$ Childhood obesity can profoundly affect children's physical health, social, and emotional well-being and self esteem. Many co-morbid conditions like metabolic, cardiovascular, orthopedic, neurological, hepatic and pulmonary disorders are also seen in association with childhood obesity. ${ }^{6}$ A systemic review showed that childhood and adolescent overweight and obesity has undesirable consequences on premature mortality and morbidity in adulthood. ${ }^{7}$ Identification of risk factors is crucial to prevent childhood obesity. Several 
studies of different countries suggest that the risk factors of obesity are multi factorial like food habit, physical activity, excess television watching, playing video games, family history of obesity, socioeconomic condition and parental education etc. 8,9 The risk factors usually are not present in isolation but in combination like genetic, physical, psychological and social factors that predict the future outcomes. ${ }^{10}$ The aim of this study was to identify the risk factors of childhood overweight and obesity in a hospital setting of Bangladesh.

\section{Materials and Methodology:}

It was a cross sectional study conducted in Paediatric Endocrine Clinic and Paediatric Outpatient Department, Bangabandhu Sheikh Mujib Medical University (BSMMU), Dhaka, Bangladesh from February, 2016 to July, 2017. Children aged 5 to 16 years attending the Paediatric Endocrine clinic and Paediatric Outpatient Department of BSMMU, Dhaka for overweight and obesity were enrolled in the study. A total of 100 children were included as cases. Children who were taking systemic steroid for any cause or any other drugs that can cause obesity and children suffering from genetic, endocrine or any neurological disease that may cause obesity were excluded from the study. In order to explore the risk factors age and sex matched normal weight children in a ratio of $2: 1$ were included in the study as control. They came with acute illness like viral fever, common cold or growing pain etc. other than overweight and obesity in Paediatric OPD. Ethical clearance was taken from Institutional Review Board, BSMMU. Informed written consent was obtained from their guardians after explaining to them the study objectives and the method of the study. A structured questionnaire was used to collect data regarding socio-demographic status like position of index case, family structure, family income level and educational status of parents etc. History of duration of outdoor play or other physical activities, availability of playground, time spend with television, computer or other electronic devices were also recorded. History of duration of breast feeding and dietary habit including main meals and snacks were taken. Standard measuring cup and spoon were used to document the approximate amount of food consumed in last 24 hours. The weight was measured by using electronic weighing machine to a nearest $100 \mathrm{gm}$ and height was recorded using locally made height board where two horizontal flat wooden boards, one for head-end another for foot-end, was attached with a long vertical scale to nearest $0.5 \mathrm{~cm}$. After measuring height and weight $\mathrm{BMI}$ was calculated and categorized as non-obese or normal weight, overweight and obese according to Centre for Disease Control and Prevention criteria. ${ }^{11}$ Children having BMI for age and sex $5^{\text {th }}$ to $<85^{\text {th }}$ percentile of reference population were classified as normal weight, children having BMI for age and sex $\geq 85$ th and $<95^{\text {th }}$ percentile of reference population were classified as overweight and children having BMI for age and sex $\geq 95^{\text {th }}$ percentile as obese. The mothers' BMI was also calculated. Statistical analysis was performed by using SPSS. Qualitative data were analyzed by Chi square test and descriptive data by proportion test or frequency distribution Table. $P$ value $\leq 0.05$ with $95 \%$ confidence interval was considered as the level of statistical significance.

\section{Result:}

In this study majority of the cases (53.0\%) belonged to the age group 10 to 16 years and controls $(60.0 \%)$ belonged to 5 to 10 years. Regarding sex of the children, majority were male in both the groups (Table I). Seventy seven percent of cases were obese

Table I

Age and Sex distribution of the respondents $(n=100+50)$

\begin{tabular}{|c|c|c|c|c|c|}
\hline & \multicolumn{2}{|c|}{ Case $(n=100)$} & \multicolumn{2}{|c|}{ Control $(n=50)$} & \multirow[t]{2}{*}{$p$ value } \\
\hline & $\mathrm{n}$ & $\%$ & $\mathrm{n}$ & $\%$ & \\
\hline \multicolumn{6}{|l|}{ Age (years) } \\
\hline $5-10$ & 47 & 47.0 & 30 & 60.0 & 0.133 \\
\hline$>10-16$ & 53 & 53.0 & 20 & 40.0 & \\
\hline \multicolumn{6}{|l|}{ Sex } \\
\hline Male & 62 & 62.0 & 31 & 62.0 & 1.000 \\
\hline Female & 38 & 38.0 & 19 & 38.0 & \\
\hline
\end{tabular}


and $23 \%$ were overweight (Table II). While analyzing the risk factors for overweight and obesity, it was found that first issue had 2.66 times, watching TV $>3$ hr had 4.47 times, breast feeding $<6$ month had 4.16 times, excess caloric intake (approx.) had 17.36 times and maternal BMI >24.9 had 2.70 times increased risk to develop obesity. In our study watching television less than three hours (OR: 0.22,
95\% Cl 0.09-0.56), breast feeding six months or more (OR: $0.24,95 \% \mathrm{Cl} 0.05-0.91$ ), less calorie intake (OR: $0.06,95 \% \mathrm{Cl} 0.02-0.15)$ and normal maternal BMI (OR: $0.37,95 \% \mathrm{Cl} 0.17-0.79$ ) had negative influence for developing overweight and obesity. No significant association was found regarding family income, family structure, mother's education level, and playing electronic or outdoor game (Table III).

Table II

Distribution of the cases by body mass index $(n=100)$

\begin{tabular}{lcc}
\hline Body mass index $\left(\mathrm{kg} / \mathrm{m}^{2}\right)$ & Number of patients & Percentage \\
\hline$\geq 85^{\text {th }}-<95$ percentile (Overweight) & 23 & 23.0 \\
$\geq 95$ th percentile (Obese) & 77 & 77.0 \\
\hline
\end{tabular}

Table III

Risk factors for development of overweight and obesity $(100+50)$

\begin{tabular}{|c|c|c|c|c|c|}
\hline Risk factors & & Casen (\%) & Controln (\%) & Odds Ratio(95\% Cl) & p value \\
\hline $1^{\text {st }}$ issue & & $62(62 \%)$ & $19(38 \%)$ & $2.66(1.25-5.70)$ & $0.005^{s}$ \\
\hline \multirow[t]{2}{*}{ Family income (Tk) } & $10000-50000$ & $82(82 \%)$ & $43(86 \%)$ & $0.74(0.26-2.07)$ & 0.535 \\
\hline & $>50000$ & $18(18 \%)$ & $07(14 \%)$ & $1.35(0.48-3.88)$ & 0.535 \\
\hline \multirow[t]{2}{*}{ Structure of family } & Nuclear & $86(86 \%)$ & $41(82 \%)$ & $1.35(0.49-3.67)$ & 0.521 \\
\hline & Joint & $14(14 \%)$ & $09(18 \%)$ & $0.74(0.27-2.04)$ & 0.521 \\
\hline \multirow[t]{2}{*}{ Mother's education level } & $\leq \mathrm{HSC}$ & $88(88 \%)$ & $45(90 \%)$ & $0.81(0.23-2.70)$ & 0.715 \\
\hline & $\geq$ Graduation & $12(12 \%)$ & $05(10 \%)$ & $1.23(0.37-4.29)$ & 0.715 \\
\hline \multirow[t]{2}{*}{ Watching TV } & $\leq 3 \mathrm{hr}$ & $54(54 \%)$ & $42(84 \%)$ & $0.22(0.09-0.56)$ & $0.001^{\mathrm{s}}$ \\
\hline & $>3 \mathrm{hr}$ & $46(46 \%)$ & $08(16 \%)$ & $4.47(1.79-11.53)$ & $0.001^{\mathrm{s}}$ \\
\hline \multirow[t]{2}{*}{ Outdoor game } & $\leq 2 \mathrm{hr}$ & $98(98 \%)$ & $48(96 \%)$ & $2.04(0.20-21.07)$ & 0.407 \\
\hline & $>2 \mathrm{hr}$ & $02(02 \%)$ & $02(04 \%)$ & $0.49(0.05-5.05)$ & 0.407 \\
\hline \multirow[t]{2}{*}{ Availability of playground } & At school & $63(63 \%)$ & $33(66 \%)$ & $0.88(0.40-1.89)$ & 0.718 \\
\hline & At or near home & $56(56 \%)$ & $23(46 \%)$ & $1.49(0.71-3.13)$ & 0.247 \\
\hline \multirow[t]{2}{*}{ Breast feeding } & $<6$ month & $21(21 \%)$ & $03(06 \%)$ & $4.16(1.09-18.60)$ & $0.018^{s}$ \\
\hline & $\geq 6$ month & $79(79 \%)$ & $47(94 \%)$ & $0.24(0.05-0.91)$ & $0.018^{\mathrm{s}}$ \\
\hline \multirow[t]{3}{*}{ Total daily caloric intake (approx.) } & Less & $11(11 \%)$ & $34(68 \%)$ & $0.06(0.02-0.15)$ & $0.001^{\mathrm{s}}$ \\
\hline & Normal & $47(47 \%)$ & $14(28 \%)$ & $2.28(1.04-5.07)$ & $0.025^{\mathrm{s}}$ \\
\hline & Excess & $42(42 \%)$ & $02(04 \%)$ & $17.38(3.82-100.0)$ & $0.001^{\mathrm{s}}$ \\
\hline \multirow[t]{2}{*}{ Mother BMI (kg/m2) } & $\leq 24.9$ & $32(32 \%)$ & $28(56 \%)$ & $0.37(0.17-0.79)$ & $0.005^{s}$ \\
\hline & $>24.9$ & $68(68 \%)$ & $22(44 \%)$ & $2.70(1.27-5.79)$ & $0.005^{\mathrm{s}}$ \\
\hline
\end{tabular}




\section{Discussion:}

Worldwide obesity and overweight is reported to be higher among adolescents specially among boys. ${ }^{12}$ In the present study majority of cases belonged to age group of 10-16 years and was male. Geckil et al. in their study included children of 5-15 years of age, among them $54.8 \%$ children were 10 years old or younger and $51.2 \%$ of them were male. ${ }^{13}$ While analyzing the risk factors, the present study found that first issue, watching television $>3$ hours per day, breastfeeding less than six month of age, taking more calorie than recommended and high maternal BMI had increased risk to develop obesity.

Hajian-Tilaki and Heidary ${ }^{14}$ showed that, most participants in their study $(67.3 \%)$ were of first birth order and only $3.3 \%$ were of birth order of 3 or higher. Our result is also consistent with this finding. Agha et al. ${ }^{15}$ found children were more likely to be obese if they belonged to families with low income, compared to families with high income. Study done in India by Tharkar and Viswanathan ${ }^{16}$ found that children and adolescents from upper socio economic status had 3.4 times higher chances of being overweight compared to those from lower socio economic status. On the other hand a Korean study reported that socioeconomic status might not be an important risk factor of obesity in children. ${ }^{17}$ However our study did not find any significant relationship between obesity and overweight with family income. Hajian-Tilaki and Heidari ${ }^{14}$ in their study found that higher maternal education at university level decreased the risk of obesity. It is to be mentioned here that most of our mothers' education were below graduation level among both the groups.

Hajian-Tilaki and Heidari ${ }^{14}$ also observed that spending $>2$ hours per day for TV watching and $>1$ hour for playing with computer games tended to increase the chances of overweight/obesity. Another study by Dennison et al. ${ }^{18}$ done in USA showed that $40 \%$ of children having a TV set in their bedroom were more prone to be overweight. The present study also found watching TV $>3$ hours as a significant risk factor for overweight or obesity. Sedentary behavior develops due to lack of outdoor games. In our study it is observed that most of the schools had small playgrounds but children were not allowed to play for long time. Fan and Jin in their study found that neighborhood parks or playground may make children more fit as they decrease BMI as well as risk of being overweight and obese ${ }^{19}$. Their result also showed that neighborhood park or playground decrease the probability of overweight and obesity by $9 \%$ and $25 \%$ for males and $17 \%$ and $28 \%$ for females but the present study did not show any significant association between availability of playground and developing obesity.

A meta-analysis showed that duration of breast feeding was inversely associated with the risk of overweight and obesity and there is $4 \%$ decrease in the risk for one month of breast feeding (OR $=0.96$ / month of breast feeding). ${ }^{20}$ We also found similar result where breast feeding $<6$ months had 4.16 times more risk for developing obesity.

Gillis et al. ${ }^{21}$ in their study done in, Canada, found that obese children consumed significantly more calorie and total fat than non-obese. The present study also found 17.34 times increased risk of obesity due to excess calorie intake. Consuming large amount of food in addition to frequent snacking of high calorie food, contribute to an excess calorie intake. Intake of high sugar containing drink is another factor that has been found as possible causal factor for development of obesity. ${ }^{22}$ In this present study incidentally we found that taking normal calorie daily was also significantly associated with development of overweight/obesity. We thought it might be due to sedentary behavior, family history of obesity or any other predisposing factors.

There is a wide evidence based support regarding association of parental obesity and childhood overweight. ${ }^{23}$ Mcloone and Morrison observed that $58 \%$ of obese children had an obese parent and the population attributable to risk percentage of child obesity associated with parental obesity was $32.5 \%$ ${ }^{24}$. Lee et al. ${ }^{17}$ in their study found that maternal overweight and obesity significantly increased the risk of childhood obesity and the present study also found similar depiction where overweight/obese mother had 2.7 times increased risk to have an obese children.

\section{Conclusion:}

The study concludes that first issue, excessive sedentary activities like watching television, lack of exclusive breast feeding, excess calorie intake and having overweight/obese mother lead to overweight or obesity in children. However further study with large sample size is needed to confirm the findings. 


\section{Acknowledgement:}

Special thanks to all children and their parents who made this study possible. This study was self funded and there was no conflict of interest.

\section{References:}

1. Dietz WH. Overweight in childhood and adolescent. The New England Journal of Medicine 2005; 350: 855-57.

2. Bhuiyan MU, Zaman S, Ahmeed T. Risk factors associated with overweight and obesity among urban school children and adolescent in Bangladesh: a case control study. BioMed Central Pediatrics 2013; 13: 72.

3. de Onis M, Blossner M, Borghi E. Global prevalence and trends of overweight and obesity among preschool children. American Journal of Clinical Nutrition 2010; 92: 1257-64.

4. Gupta N, Shah P, Nayyar S and Misra A. Childhood obesity and metabolic syndrome in developing countries. Indian Journal of Pediatrics 2013; 80: 28-37.

5. Bulbul T, Hoque M. Prevalence of childhood obesity and overweight in Bangladesh: findings from a countrywide epidemiological study. BioMed Central Pediatrics 2014; 14: 86.

6. Sahoo K, Sahoo B, Choudhury AK, Sofi NY, Kumer R, Bhadotia AS. Childhood obesity: causes and consequences. Journal of Family Medicine and Primary Care 2015; 4: 187-192.

7. Reilly JJ, Kelly J. Long-term impact of overweight and obesity in childhood and adolescence on morbidity and premature mortality in adulthood: systematic review. International Journal of Obesity 2011; 357: 891898.

8. Mozaffari $\mathrm{H}$, Nabaei B. Obesity and related risk factor. Indian Journal of Pediatrics 2007; 74: 264-267.

9. Giugliano R, Carneiro EC. Factors associated with obesity in school children. Journal of Pediatrics (Rio J) 2004; 80: 17-22.

10. Birch LL, Anzman SL. Learning to eat in an obesogenic environment: A developmental systems perspective on childhood obesity. Child Development Perspective 2010; 4: 138-143.
11. Ogden CL, Flegal KM. Changes in terminology for childhood overweight and obesity. National health statistics reports; no 25. National Center for Health Statistics. 2010.

12. Bibiloni MDM, Pons A, Tur JA. Prevalence of overweight and obesity in adolescents: A systemic review. International Scholarly Research Notices Obesity 2013; 2013: 1-14.

13. Geckil E, Aslan S, Ister ED, Simsek DK, Sahin T. Prevalence and Risk Factors of Obesity and Overweight in Elementary School-Age (5 to 15 Years Old) Children in South-eastern Turkey. Iran Journal of Pediatrics 2017; 27: 7218.

14. Hajian-Tilaki K, Heidari B. Childhood Obesity, overweight, socio-demographic and life style determinants among preschool children in Babol, Northern Iran. Iranian Journal Public Health 2013; 42: 1283-1291.

15. Al-Agha E, Tatwany B, Aiash D, Mandourah LA, Bukhalil TN. The Effect of socioeconomic status, number of siblings and parental of education on children body mass index at Jeddah, Saudi Arabia: Cross sectional study. Family Medicine and Medical Science Research 2015; 4: 184188.

16. Tharkar S, Viswanathan V. Impact of socioeconomic status on prevalence of overweight and obesity among children and adolescent in Urban India. The Open Obesity Journal 2009; 1: 9-14.

17. Lee HJ, Kim SH, Choi SH, Lee JS. The association between socioeconomic status and obesity in Korian children: An analysis of the Fifth Korea National Health and Nutrition Examination Survey (2010-2012). Pediatric Gastroenterology, Hepatology and Nutrition 2017; 20: 186-193.

18. Dennison BA, Erb TA, Jenkins PL. Television viewing and television in bedroom associated with overweight risk among low-income preschool children. Pediatrics 2002; 9: 10281035.

19. Fan M, Jin Y. Do neighborhood parks and playgrounds reduce childhood obesity? American Journal of Agricultural Economics 2014; 96: 26-42. 
BANGLADESH J CHILD HEALTH 2019; VOL 43 (1) : $14 \quad$ Risk Factors for Overweight and Obesity among Children \& Adolescents

20. Harder T, Bergmann R, Kallischnigg G, Plagemann A. Duration of breast feeding and risk of overweight: A meta-analysis. American Journal of Epidemiology 2005; 162: 397-403.

21. Gillis LI, Kennedy LC, Gillis AM, Bar O. Relationship between juvenile obesity, dietary energy and fat intake and physical activity. International Journal of Obesity 2002; 26 : 458-463.
22. Anderson MP, Butcher FK. Childhood Obesity: Trends and Potential causes. The Future of Children 2006; 1: 1-27.

23. Dipty AD, McBride BA, Fiese BH, Jones BL, Cho $H$. Risk factors for overweight/obesity in preschool children: An ecological approach. Childhood Obesity 2013; 9: 399-409.

24. McLoone P, Morrison SD. Risk of childhood obesity from parental obesity: analysis of repeat national cross-sectional surveys. European Journal of Public Health 2012; 24: 186-190. 